Article

\title{
Solubility and Diffusivity of Polar and Non-Polar Molecules in Polyethylene-Aluminum Oxide Nanocomposites for HVDC Applications
}

\author{
Shima L. Holder *, Mattias E. Karlsson, Richard T. Olsson, Mikael S. Hedenqvist ${ }^{\circledR}$ and \\ Fritjof Nilsson *(1) \\ Department of Fibre and Polymer Technology, School of Engineering Sciences in Chemistry, Biotechnology and \\ Health, KTH Royal Institute of Technology, 10044 Stockholm, Sweden; mekarls@kth.se (M.E.K.); \\ rols@kth.se (R.T.O.); mikaelhe@kth.se (M.S.H.) \\ * Correspondence: holder@kth.se (S.L.H.); fritjofn@kth.se (F.N.)
}

Received: 7 January 2020; Accepted: 3 February 2020; Published: 7 February 2020

check for updates

\begin{abstract}
The best commercial high-voltage insulation material of today is (crosslinked) ultra-pure low-density polyethylene (LDPE). A 100-fold decrease in electrical conductivity can be achieved by adding 1-3 wt.\% of well-dispersed inorganic nanoparticles to the LDPE. One hypothesis is that the nanoparticle surfaces attract ions and polar molecules, thereby cleaning the surrounding polymer, and thus reducing the conductivity. LDPE-based nanocomposites with 1-12 wt.\% octyl-coated aluminum oxide nanoparticles were prepared and the sorption and desorption of one polar compound (acetophenone, a crosslinking by-product) and one non-polar compound of a similar size (limonene) were examined. Since the uptake of acetophenone increased linearly with increasing filler content, whereas the uptake of limonene decreased, the surface attraction hypothesis was strengthened. The analytical functions for predicting composite solubility as a function of particle size and filler fraction were derived using experimental solubility measurements and Monte Carlo simulations.
\end{abstract}

Keywords: LDPE; HVDC; nanocomposites; solubility; acetophenone; limonene

\section{Introduction}

In order to transport renewable electrical energy across continents with tolerably low energy losses, the voltage levels for the next generation of high-voltage direct-current (HVDC) cables must increase from today's $640 \mathrm{kV}$ to 1-2 MV. To achieve this voltage increase, improved insulation materials must be developed. Ultrapure low-density polyethylene (LDPE) has a low electrical conductivity and is, therefore, the dominating HVDC insulating material today. A higher thermal stability is achieved by crosslinking the polyethylene (XLPE), but chemical crosslinking with peroxides produces polar species (e.g., acetophenone, cumyl alcohol) which increase the electrical conductivity. For instance, a five-fold conductivity increase was observed for (non-degased) XLPE, compared to the corresponding LDPE, when measured at $60 \mathrm{kV} / \mathrm{mm}, 20^{\circ} \mathrm{C}$ and $6 \mathrm{~h} \mathrm{[1].} \mathrm{This} \mathrm{unwanted} \mathrm{effect} \mathrm{can} \mathrm{be} \mathrm{reduced} \mathrm{by}$ minimizing the initial peroxide concentration and by degassing the XLPE after the reaction [2,3]. After careful degasing, the difference in conductivity between XLPE and LDPE approaches zero [1,4], but the degasing process is generally time- and energy-consuming and thus is not ideal for the environment. Two main strategies for reducing the electrical conductivity of the polyethylene have been proposed, either blending small fractions of high density polyethylene (HDPE) with the LDPE [4] or dispersing small fractions (1-3 wt.\%) of metal oxide nanoparticles (e.g., $\mathrm{Al}_{2} \mathrm{O}_{3}, \mathrm{MgO}$ and $\mathrm{ZnO}$ ) in the LDPE [5-9]. The nanocomposite strategy gives a larger reduction in electrical conductivity ( $\sim 30$ times for $3 \mathrm{wt} . \%$ $\mathrm{Al}_{2} \mathrm{O}_{3}$ at $32.5 \mathrm{kV} / \mathrm{mm}, 60^{\circ} \mathrm{C}, 11 \mathrm{~h}$, Figure 1 [7]), but the physical mechanism behind the conductivity improvement and the reason for the local optimum, around $3 \mathrm{wt} . \%$ nanoparticles, is still under debate. 


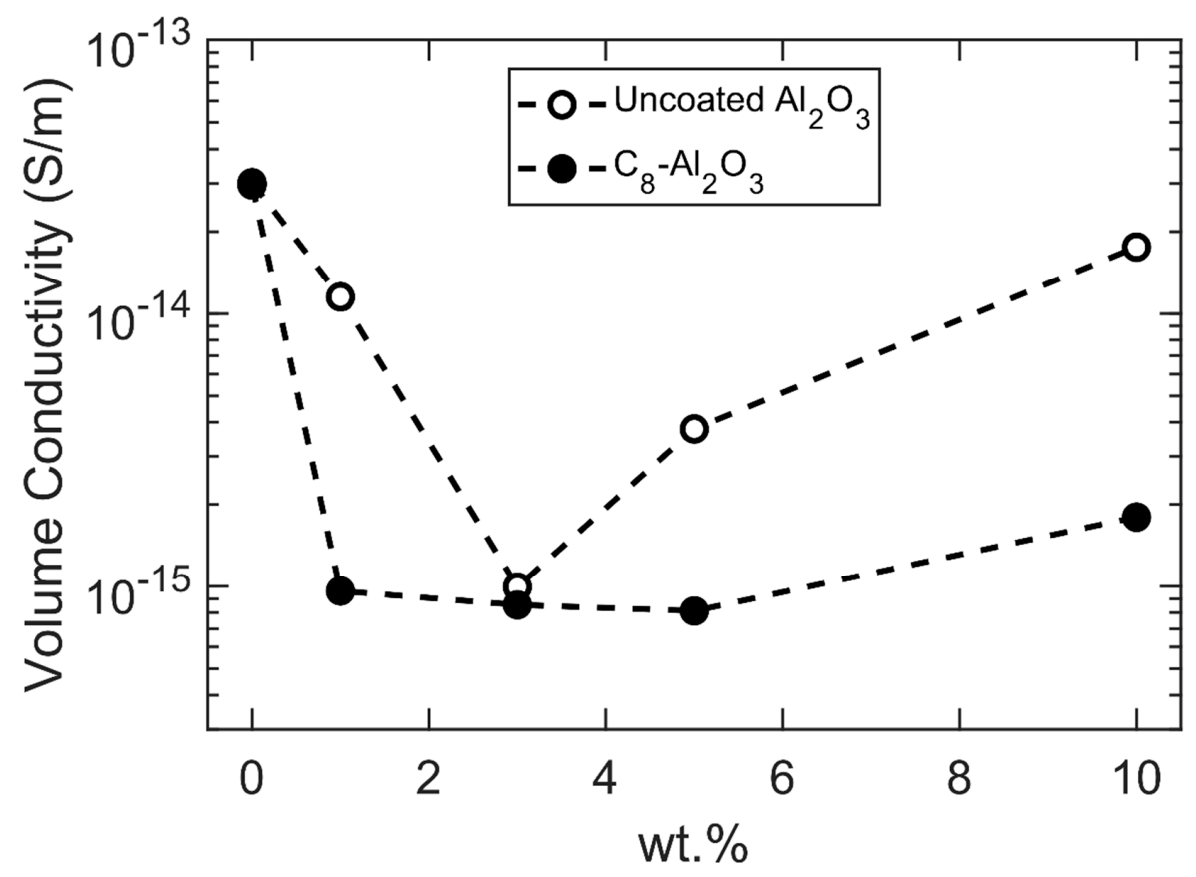

Figure 1. Volume conductivity $\left(32.5 \mathrm{kV} / \mathrm{mm}, 60^{\circ} \mathrm{C}, 11 \mathrm{~h}\right)$ as a function of $\mathrm{Al}_{2} \mathrm{O}_{3}$ nanoparticle fraction, with and without octyl coating. Reproduced from [7], IEEE: 2017.

One hypothesis for the conductivity reduction in nanocomposites is that electrons and holes are trapped in deep traps in the nanoparticle surface [10-13]. A complementary hypothesis is that ions and molecules with permanent dipole moments, such as water and crosslinking by-products, are also attracted and adsorbed onto the nanoparticles, resulting in the cleaning of the polyethylene matrix $[9,14]$. Liu et al. (2016) [14] reported that nanoparticles $\left(\mathrm{Al}_{2} \mathrm{O}_{3}, \mathrm{MgO}\right.$ and $\left.\mathrm{ZnO}\right)$ suspended in (hydrophobic) heptane can adsorb polar molecules (water, dicumyl peroxide, acetophenone and cumyl alcohol) and that selective adsorption can be achieved by coating the nanoparticle surface. The surface coating could be tailored to adsorb small, undesired impurities, such as acetophenone, but not the larger antioxidants. Nilsson et al. (2017) [8] reported that the water solubility of MgO/LDPE nanocomposites increased significantly with increasing MgO filler content and utilized Finite Element Modeling (FEM) to predict how the increased solubility would affect the electrical conductivity. A minimum of conductivity was predicted at around $3 \mathrm{wt} . \%$, because at higher filler fractions, the particles can both agglomerate and form conductive paths through the material. Conductivity measurements confirmed the FEM predictions. At a low relative humidity $(\mathrm{RH})(\sim 0 \%)$, the conductivity was lowest in the presence of 1-3 wt.\% nanoparticles, but at a high RH ( 50\%), pure polyethylene (PE) had the lowest conductivity.

A low electrical conductivity is a necessary condition for a good HVDC insulator material, but several other electrical and mechanical properties are also of importance. Fortunately, $\mathrm{PE} / \mathrm{Al}_{2} \mathrm{O}_{3}$ nanocomposites typically have improved properties when compared to pure $\mathrm{PE}$, including a reduced space charge accumulation [15-18] dielectric permittivity [19,20] and thermal conductivity [12]. Additionally, an increased elastic modulus [21,22], tensile strength [23] thermal stability [22] and dielectric breakdown strength $[15-17,24]$ has been reported. Good reviews on nanocomposites for electrical applications include [6,25-31].

In this study, the sorption and desorption of penetrant molecules in non-crosslinked LDPE- $\mathrm{Al}_{2} \mathrm{O}_{3}$ nanocomposites were examined to test the hypothesis that the nanoparticles attract polar molecules and clean the surrounding polyethylene polymer matrix. The transport performance of acetophenone (the polar compound) and limonene (the non-polar compound) was, therefore, assessed. Acetophenone $\left(\mathrm{C}_{6} \mathrm{H}_{5} \mathrm{COCH}_{3}\right)$, which is an LDPE crosslinking by-product, was chosen because of its undesired presence in today's commercial HVDC insulation materials. Limonene $\left(\mathrm{C}_{10} \mathrm{H}_{16}\right)$ was chosen because of its distinct non-polar character, with octanol/water partition coefficient $\log \left(K_{\text {ow }}\right)=4.57$ [32] when 
compared to 1.58 [33] for acetophenone. Since the chemical structures and molar masses of limonene $(136 \mathrm{~g} / \mathrm{mol})$ and acetophenone $(120 \mathrm{~g} / \mathrm{mol})$ were comparable, the influence of polarity on diffusivity and solubility was expected to be comparatively easy to isolate.

\section{Material and Methods}

\subsection{Material Preparation (LDPE and $\mathrm{LDPE} / \mathrm{Al}_{2} \mathrm{O}_{3}$ Nanocomposites)}

The polyethylene plates were produced by the extrusion and compression molding of LDPE pellets $\left(\mathrm{M}_{\mathrm{w}}: 75 \mathrm{kDa}\right.$ [7], Borealis AB (Stenungsund, Sweden)). The LDPE pellets were first immersed in liquid nitrogen for $1 \mathrm{~h}$ and then cryo-ground into powder. Subsequently, the powder was mixed with $n$-heptane. After $12 \mathrm{~h}$ drying in air at $80^{\circ} \mathrm{C}$, the LDPE powder was processed $\left(6 \mathrm{~min}, 150{ }^{\circ} \mathrm{C}, 100 \mathrm{rpm}\right)$ in a mini-extruder (Micro $5 \mathrm{cc}$ Twin Screw Compounder, DSM Xplore). The extruded rods were vacuum dried $\left(80^{\circ} \mathrm{C}, 12 \mathrm{~h}\right.$ ), pelletized and compression molded (LabPro 400 Press, Frontlijne Grotnes (Niles, MI, USA)) at $130^{\circ} \mathrm{C}$ into $300 \mu \mathrm{m}$ hick plaques. Polyethylene terephthalate (PET) films were used as anti-sticking layers between the metal press plates and the LDPE. During the compression molding, a contact pressure was first applied $\left(5-8 \mathrm{kN}, 10 \mathrm{~min}\right.$, ramping to $\left.130^{\circ} \mathrm{C}\right)$, followed by compression $\left(200 \mathrm{kN}, 10 \mathrm{~min}, 130^{\circ} \mathrm{C}\right)$ and, finally, cooling back to room temperature ( $\left.200 \mathrm{kN}, 7 \mathrm{~min}\right)$ [34]. Reference samples were also produced by compression molding the virgin (non-extruded) LDPE pellets.

The corresponding LDPE- $\mathrm{Al}_{2} \mathrm{O}_{3}$ nanocomposite plates were made with the same protocol, with the only difference being that $1-12 \mathrm{wt} . \% \mathrm{Al}_{2} \mathrm{O}_{3}$ nanoparticles were added to the LDPE matrix before extrusion. The aluminum oxide nanoparticles (Nanodur, Nanophase Inc. (Romeoville, IL, USA), density $3.97 \mathrm{~g} / \mathrm{cm}^{3}$, diameter $50 \mathrm{~nm}$, CAS number 1344-28-01) were used with or without an octyl(triethoxy)silane $\left(C_{8}\right)$ coating. The $C_{8}$ surface modification was performed by dispersing nanoparticles in a mixture of water and 2-propanol. $25 \mathrm{wt} . \%$ ammonia (Sigma-Aldrich (St. Louis, MO, USA)) was added and the slurry was mechanically stirred for 5 min before $n$-octyl(triethoxy)silane (CAS-number 2943-75-1, 276.5 Da) was inserted. The suspension was allowed to react for 24 at $20^{\circ} \mathrm{C}$ before the coated particles were washed and dried overnight [7]. All nanoparticles were soaked in $5 \mathrm{~mL}$ heptane, ultrasonicated $(10 \mathrm{~min})$ and mixed with LDPE powder. The resulting slurry was shaken for $60 \mathrm{~min}$ in a Vortex Genie 2 shaker (G560E, Scientific Industries (Bohemia, NY, USA)) and then dried overnight at $80^{\circ} \mathrm{C}$ before extrusion and compression molding.

\subsection{Material Characterization}

Scanning electron microscopy (SEM) was used to study the nanoparticle dispersion and the crystal morphology of the materials. $0.3 \mathrm{~mm}$ thick circular pieces of each plaque sample were freeze-cracked in liquid nitrogen and acid-etched in a $10 \mathrm{mg} \mathrm{KMnO} / 1 \mathrm{~mL}$ acid $\left(\mathrm{H}_{2} \mathrm{SO}_{4}: \mathrm{H}_{3} \mathrm{PO}_{4}: \mathrm{H}_{2} \mathrm{O}\right.$ (10:4:1)) solution

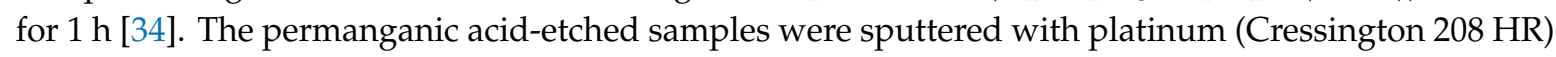
$(20 \mathrm{~s}, 80 \mathrm{~mA})$ and the cross-sectional morphology was examined with a Hitachi S-4800 field emission SEM. The fracture surfaces were analysed to ensure that the bulk material, rather than the surface, was investigated. The microstructure of $\mathrm{LDPE} / \mathrm{Al}_{2} \mathrm{O}_{3}$ nanocomposites has also been carefully examined with SEM and transmission electron microscope TEM in our previous studies $[7,35,36]$.

A differential scanning calorimeter (DSC 1) from Mettler Toledo was used for the calorimetric measurements and for determining endotherms. For each material, $5 \pm 0.05 \mathrm{mg}$ was placed in a covered aluminum pan, which was put into the DSC. A $50 \mathrm{~mL} \mathrm{~min}^{-1}$ nitrogen environment was used. The temperature was ramped three times at a rate of $10^{\circ} \mathrm{C} \mathrm{min}^{-1}$-first from -50 to $200{ }^{\circ} \mathrm{C}$, then to $-50^{\circ} \mathrm{C}$ and, finally, to $200{ }^{\circ} \mathrm{C}$. Between the temperature ramps, the temperature was kept constant for $5 \mathrm{~min}$. The crystallinity and the melting peak temperature were evaluated from the first heating scan, to include the thermal history of the samples. Using the melting enthalpy $\left(\Delta h_{f}\right)$ and the melting onset temperature $\left(T_{1}\right)$ from the DSC measurements, the mass crystallinity $\left(W_{c}\right)$ was assessed by the total enthalpy method [37]: 


$$
W_{c}=\frac{\Delta h_{f}}{\Delta h_{f}^{0}-\int_{T_{1}}^{T_{m}^{0}}\left(c_{p, a}-c_{p, c}\right) d T} \times 100
$$

where $T_{m}^{0}=414.6 \mathrm{~K}$ [37] is the equilibrium melting point of $\mathrm{PE}, \Delta h_{f}^{0}=293 \mathrm{~J} \mathrm{~g}^{-1}$ [37] is the melting enthalpy for $100 \%$ crystalline PE and $c_{p, a}$, and $c_{p, c}$ are the heat capacities for amorphous and crystalline LDPE, respectively $[38,39]$. The crystal thickness $L_{c}(\mathrm{~nm})$ was assessed by applying the Thomson-Gibbs equation to the melting temperature data, using a crystal density of $\rho_{c}=1000 \mathrm{~kg} / \mathrm{m}^{3}$ and a fold surface energy of $\sigma_{0}=90 \mathrm{~mJ} / \mathrm{m}^{2}$ [37]:

$$
L_{c}=\left(\frac{2 \sigma_{0}}{\Delta h^{0} \rho_{c}}\right)\left(\frac{T_{m}^{0}}{T_{m}^{0}-T_{m}}\right)=0.614\left(\frac{T_{m}^{0}}{T_{m}^{0}-T_{m}}\right)
$$

The Archimedes principle (with water) was used to measure the sample density $\rho$. The densities for $\mathrm{Al}_{2} \mathrm{O}_{3}$ and LDPE were $\rho_{1}=3900 \mathrm{~kg} / \mathrm{m}^{3}$ [40] and $\rho_{2}=927 \mathrm{~kg} / \mathrm{m}^{3}$ (measured), respectively. At particle weight fraction $\phi$, the porosity was calculated as the ratio between $\rho$ and the predicted density $\rho_{0}=$ $\left(\rho_{1} \rho_{2} /\left(\phi \rho_{2}+(1-\phi) \rho_{1}\right)\right.$.

\subsection{Solubility (Sorption-Desorption)}

The solubility was defined as the equilibrium mass fraction (wt.\%) of the solutes (acetophenone or limonene) in the materials. The solubility was calculated from the absolute difference between the initial mass and the final (steady state) mass, either from a sorption or a desorption experiment. Sorption measurements were done by immersing $0.3 \mathrm{~mm}$ thick and $2.5 \mathrm{~cm}$ wide quadratic samples in tubes filled with acetophenone or limonene. The samples were removed at predefined time intervals. They were dried with clean serviettes, to get rid of excess solute on the surfaces, and then rapidly weighed before they were returned to the tubes. The weighing process continued until constant mass was reached. The desorption measurements were done by removing the saturated samples from the liquid and drying them in air. The weight was recorded over time until equilibrium was reached. The solubility of the limonene was measured at room temperature $\left(21^{\circ} \mathrm{C}\right)$, while acetophenone solubility was measured at both 21 and $60^{\circ} \mathrm{C}$. A single solubility measurement was done for each material/solute combination. The standard deviation estimates were assessed using a five-fold replicate of each solute.

\subsection{Diffusivity (Sorption/Desorption)}

For each material, the diffusivity $(D)$ of acetophenone and limonene was calculated. The first strategy was to measure and utilize the time $t_{0.5}$, which is the time to reach $50 \%$ of the equilibrium concentration for a flat sample with thickness $l$ [41]:

$$
D=0.04919 /\left(t_{0.5} / l^{2}\right)
$$

This is an approximate method, considering that $D$ is actually concentration dependent. A more elaborate strategy was to use a concentration dependent diffusivity $D(c)$ and fit the experimental sorption/desorption data with Fick's second law of diffusion [40]:

$$
\frac{\partial c}{\partial t}=\frac{\partial c}{\partial x}\left(D(c) \frac{\partial c}{\partial x}\right)
$$

Equation (4) was discretized and solved using an implicit finite difference multistep method [42,43]. The diffusivity $D(c)$ was described by an exponential function, where $D_{c 0}$ is the zero-concentration diffusivity and $\alpha$ is the plasticisation power [43]: 


$$
D(c)=D_{c 0} \exp (\alpha c)
$$

This is a semi-empirical equation which has been shown to properly describe the solute diffusivity of a number of systems [42-44]. During sorption, the concentration at the outer boundary was constant $\left(c=c^{\mathrm{eq}}\right)$, while during desorption, the boundary concentration was set to zero.

\section{Results and Discussion}

\subsection{Material Characterization (SEM, Porosity and DSC)}

Figure 2 reveals the composite structure of pristine LDPE and the LDPE-based nanocomposites with 3 wt. $\% \mathrm{Al}_{2} \mathrm{O}_{3}, 12 \mathrm{wt} . \% \mathrm{Al}_{2} \mathrm{O}_{3}$ and $12 \mathrm{wt} . \% \mathrm{C}_{8}-\mathrm{Al}_{2} \mathrm{O}_{3}$. The uncoated $\mathrm{Al}_{2} \mathrm{O}_{3}$ nanoparticles agglomerated at high filler fractions, whereas the coated $\mathrm{C}_{8}-\mathrm{Al}_{2} \mathrm{O}_{3}$ nanoparticles showed good dispersion, even at $12 \mathrm{wt} . \%$. The addition of nanoparticles did not change the morphology of the LDPE component notably. A more detailed analysis of these $\mathrm{LDPE} / \mathrm{Al}_{2} \mathrm{O}_{3}$ microstructures was presented in our previous studies $[7,35,36]$.

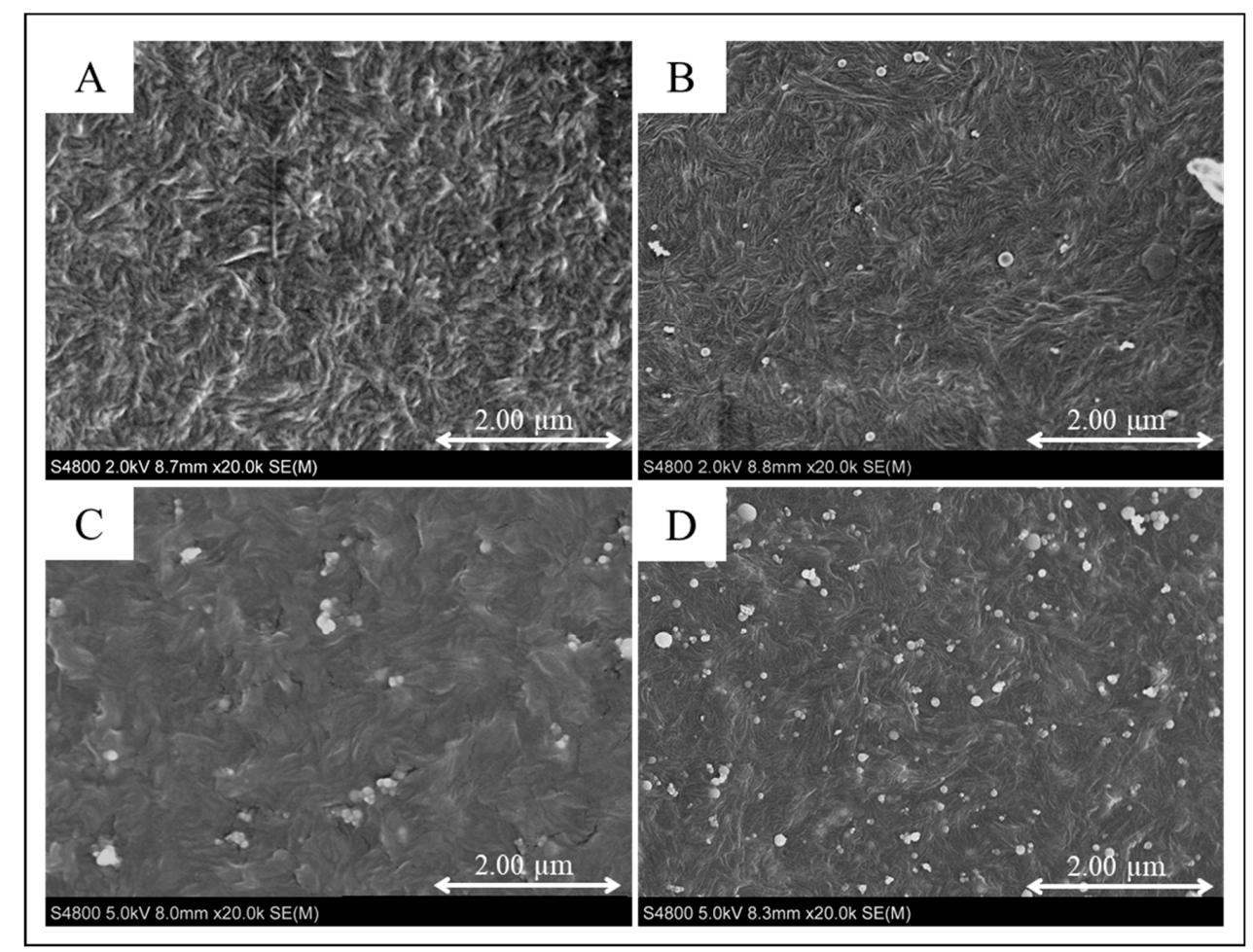

Figure 2. SEM micrographs of extruded, compression molded, freeze-cracked, acid-etched LDPE-based nanocomposites: (A) LDPE, (B) 3 wt. $\% \mathrm{Al}_{2} \mathrm{O}_{3}$, (C) $12 \mathrm{wt} . \% \mathrm{Al}_{2} \mathrm{O}_{3}$ and (D) $12 \mathrm{wt} . \% \mathrm{C}_{8}-\mathrm{Al}_{2} \mathrm{O}_{3}$.

The porosity, calculated from the measured nanocomposite densities $\left(928-998 \mathrm{~kg} / \mathrm{m}^{3}\right)$, increased slightly with particle filler fraction for all materials, but the overall porosity was very low. Although the uncoated nanoparticles gave slightly higher porosities than the octyl-coated ones, the maximum porosity among all samples was still less than $0.7 \%$.

The DSC measurements indicated no significant difference between extruded LDPE and extruded LDPE nanocomposites containing 3-12 wt. $\% \mathrm{Al}_{2} \mathrm{O}_{3}$ or $\mathrm{C}_{8}-\mathrm{Al}_{2} \mathrm{O}_{3}$ (Table 1). The peak melting temperature $\left(T_{m}\right)$ was $112 \pm 1{ }^{\circ} \mathrm{C}$, the melting onset temperature $\left(T_{1}\right)$ was $99.2 \pm 0.3^{\circ} \mathrm{C}$ and the lamellar thickness $\left(L_{c}\right)$ associated with the peak melting temperature, calculated using the Gibbs-Thomson equation [37], was $8.6 \pm 0.3 \mathrm{~nm}$ for all materials. The crystallinity of extruded LDPE was $50 \%$ and there was no systematic trend in the nanocomposite crystallinity $(50 \pm 3 \%)$. Overall, the addition of nanoparticles 
had a limited impact on the crystalline nanostructure, as qualitatively confirmed with SEM (Figure 1). However, the non-extruded LDPE had a slightly lower crystallinity $(45.5 \%)$ than that of the extruded materials $(50 \%)$.

Table 1. Thermal characterization of the LDPE-based materials.

\begin{tabular}{|c|c|c|c|c|}
\hline \multirow{2}{*}{ Sample } & \multicolumn{4}{|c|}{ Property } \\
\hline & $T_{m}{ }^{\mathrm{a}}\left({ }^{\circ} \mathrm{C}\right)$ & $T_{c}{ }^{b}\left({ }^{\circ} \mathrm{C}\right)$ & $L_{c}^{\mathrm{c}}(\mathrm{nm})$ & $W_{c}^{d}(\%)$ \\
\hline PE (powder) ${ }^{b}$ & 112.8 & 98.9 & 8.9 & 46 \\
\hline PE-Hept (extruded) & 111.1 & 99.1 & 8.6 & 50 \\
\hline PE-3wt. $\%-\mathrm{Al}_{2} \mathrm{O}_{3}-\mathrm{PNC}$ & 112.3 & 99.1 & 8.7 & 50 \\
\hline PE-6wt. $\%-\mathrm{Al}_{2} \mathrm{O}_{3}-\mathrm{PNC}$ & 111.6 & 99.1 & 8.5 & 48 \\
\hline PE-9wt. $\%-\mathrm{Al}_{2} \mathrm{O}_{3}-\mathrm{PNC}$ & 111.5 & 99.1 & 8.5 & 47 \\
\hline PE-12wt. $\%-\mathrm{Al}_{2} \mathrm{O}_{3}$-PNC & 113.0 & 98.9 & 8.9 & 49 \\
\hline PE-3wt. $\%-\mathrm{C}_{8}-\mathrm{Al}_{2} \mathrm{O}_{3}-\mathrm{PNC}$ & 111.8 & 99.3 & 8.5 & 52 \\
\hline PE-6wt. $\%-\mathrm{C}_{8}-\mathrm{Al}_{2} \mathrm{O}_{3}-\mathrm{PNC}$ & 111.7 & 99.3 & 8.5 & 53 \\
\hline PE-9wt. $\%-\mathrm{C}_{8}-\mathrm{Al}_{2} \mathrm{O}_{3}-\mathrm{PNC}$ & 110.9 & 99.5 & 8.3 & 50 \\
\hline PE-12wt. $\%-\mathrm{C}_{8}-\mathrm{Al}_{2} \mathrm{O}_{3}-\mathrm{PNC}$ & 112.8 & 99.1 & 8.9 & 49 \\
\hline
\end{tabular}

${ }^{\mathrm{a}} T_{m}=$ peak melting temperature from the first melting curve with heating rate of $10^{\circ} \mathrm{C} / \mathrm{min}^{\mathrm{b}}{ }^{\mathrm{b}} T_{c}=$ crystallization temperature with cooling rate of $10{ }^{\circ} \mathrm{C} / \mathrm{min} ;{ }^{\mathrm{c}} L_{c}=$ lamellar thickness calculated using $T_{m} ;{ }^{\mathrm{d}} W_{c}=$ weight percent crystallinity calculated from the first heating curve.

\subsection{Solubility}

The solubility of (polar) acetophenone in LDPE-based nanocomposites was plotted as a function of nanoparticle content in Figure 3a, using desorption data taken at $21^{\circ} \mathrm{C}$ (Table 2). The solubility increased linearly, with increasing filler fraction for both $\mathrm{PE}-\mathrm{Al}_{2} \mathrm{O}_{3}$ and $\mathrm{PE}-\mathrm{C}_{8}-\mathrm{Al}_{2} \mathrm{O}_{3}$ nanocomposites. The slope increase was lower for the latter, because the $\mathrm{C}_{8}$-coating made the particles more hydrophobic, which reduced their ability to adsorb the polar acetophenone. The linear functions are due to (1) the fact that an isolated nanoparticle can adsorb a fixed amount of acetophenone onto its surface and (2), at low filler content, the particles are well separated and do not interfere with each other [8]. The nanoparticles had a lower impact on the acetophenone solubility than on the water solubility $[8,45]$. However, the results still show that metal oxide nanoparticles such as $\mathrm{Al}_{2} \mathrm{O}_{3}$ can adsorb polar molecules, also larger than water, and thereby clean the surrounding polymer matrix from conductivity influencing impurities. At $60{ }^{\circ} \mathrm{C}$, the acetophenone solubility was higher than at RT ( $5 \mathrm{wt} . \%$ versus $\left.\sim 2 \mathrm{wt} . \%\right)$, probably due to the higher accessible free volume after temperature-induced polymer swelling [46].

Table 2. Solubility and diffusivity. Acetophenone desorption data at $21^{\circ} \mathrm{C}$.

\begin{tabular}{|c|c|c|c|}
\hline Sample & Solubility (wt.\%) & $\begin{array}{l}D \text { (Equation (3)) } \\
\left(\times 10^{-9} \mathrm{~cm}^{2} \mathrm{~s}^{-1}\right)\end{array}$ & $\begin{array}{c}D_{c 0} \text { (Equation (5)) } \\
\left(\times 10^{-9} \mathrm{~cm}^{2} \mathrm{~s}^{-1}\right)\end{array}$ \\
\hline PE (extruded) & 2.1 & 5.1 & 4.3 \\
\hline PE-3wt. $\%-\mathrm{Al}_{2} \mathrm{O}_{3}-\mathrm{PNC}$ & 2.1 & 5.6 & 4.4 \\
\hline PE-6wt. $\%-\mathrm{Al}_{2} \mathrm{O}_{3}-\mathrm{PNC}$ & 2.3 & 6.1 & 3.8 \\
\hline PE- 9 wt. $\%-\mathrm{Al}_{2} \mathrm{O}_{3}-\mathrm{PNC}$ & 2.4 & 5.9 & 3.9 \\
\hline PE- 12 wt. $\%-\mathrm{Al}_{2} \mathrm{O}_{3}-\mathrm{PNC}$ & 2.5 & 5.8 & 3.4 \\
\hline PE-3wt. $\%-C 8-\mathrm{Al}_{2} \mathrm{O}_{3}-\mathrm{PNC}$ & 2.1 & 6.3 & 4.5 \\
\hline PE-6wt.\%-C8- $\mathrm{Al}_{2} \mathrm{O}_{3}-\mathrm{PNC}$ & 2.2 & 5.8 & 4.2 \\
\hline PE-9wt.\%-C8- $\mathrm{Al}_{2} \mathrm{O}_{3}-\mathrm{PNC}$ & 2.3 & 5.7 & 4.1 \\
\hline PE-12wt.\%-C8- $\mathrm{Al}_{2} \mathrm{O}_{3}-\mathrm{PNC}$ & 2.4 & 6.1 & 3.9 \\
\hline
\end{tabular}

The (non-polar) limonene equilibrium mass uptake, measured during desorption at $21^{\circ} \mathrm{C}$, decreased linearly with nanoparticle filler fraction for both $\mathrm{Al}_{2} \mathrm{O}_{3}$ and $\mathrm{C}_{8}-\mathrm{Al}_{2} \mathrm{O}_{3}$ nanoparticles (Figure $3 \mathrm{~b}$, Table 3). This is in direct contrast with the trend for acetophenone, where the solubility increased linearly with the filler fraction. The limonene uptake in LDPE was clearly higher ( 13 wt.\%) than the corresponding acetophenone uptake $(\sim 2 \mathrm{wt} . \%)$, due to the non-polar character of both LDPE and limonene. 


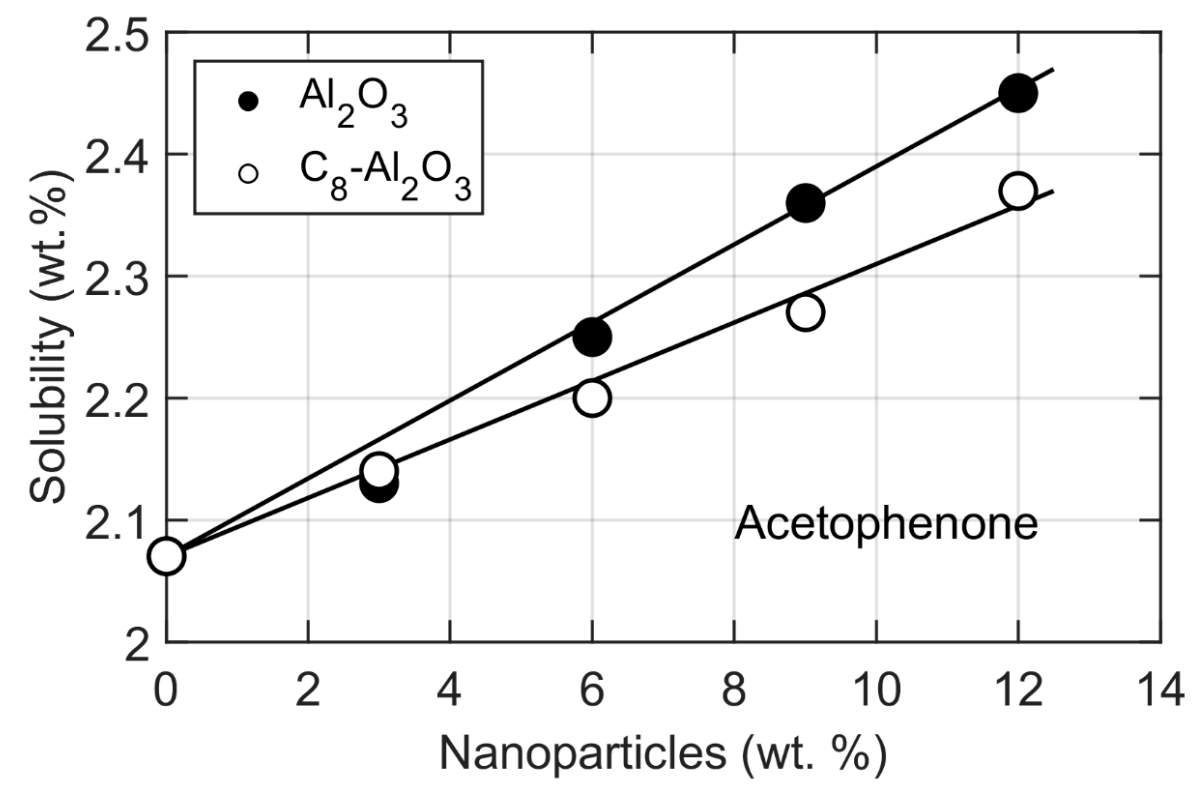

(a)

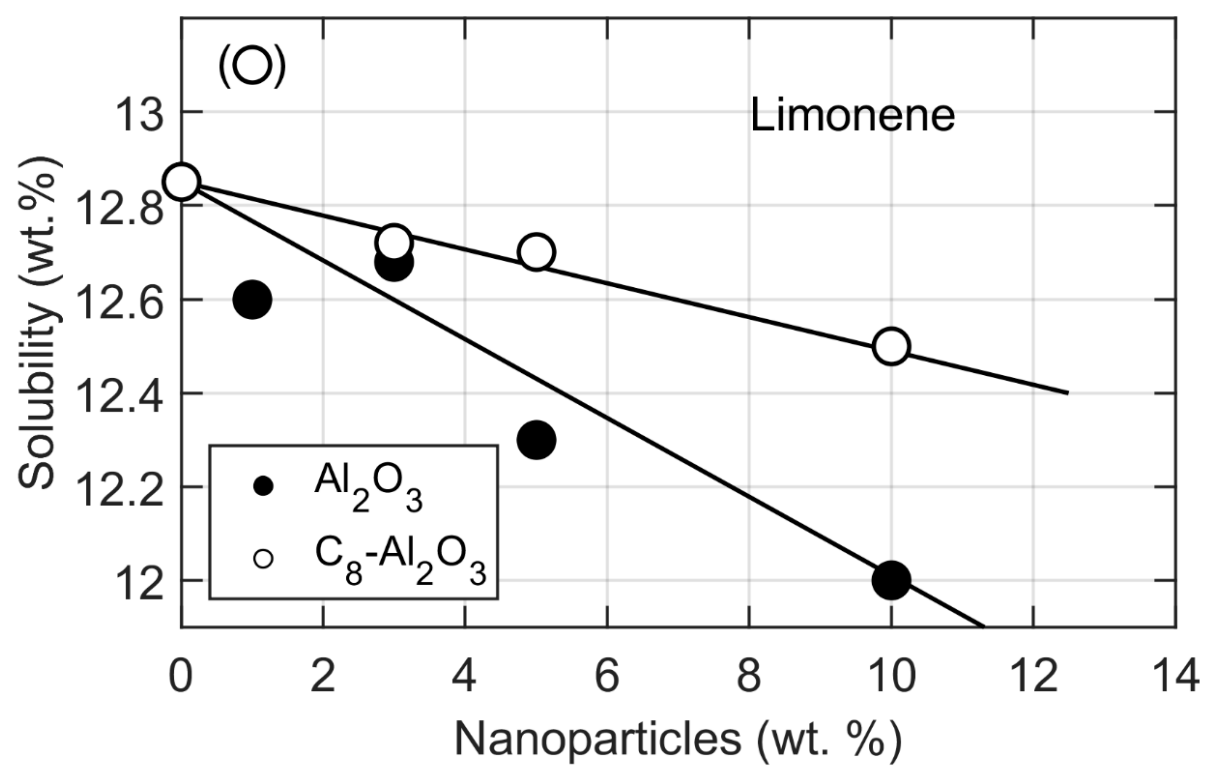

(b)

Figure 3. Desorption solubility $\left(21^{\circ} \mathrm{C}\right)$ as function of particle wt.\%. (a) Acetophenone, (b) limonene. The standard deviation was $0.02 \mathrm{wt} \%$ for acetophenone and $0.10 \mathrm{wt} \%$ for limonene, based on 5 replicates per solute for each filler fraction.

Table 3. Solubility and diffusivity. Limonene desorption data at $21^{\circ} \mathrm{C}$.

\begin{tabular}{|c|c|c|}
\hline Sample & Solubility (wt.\%) & $D$ (Equation (3)) $\left(\times 10^{-9} \mathrm{~cm}^{2} \mathrm{~s}^{-1}\right)$ \\
\hline PE (extruded) & 12.9 & 29 \\
\hline PE-1wt. $\%-\mathrm{Al}_{2} \mathrm{O}_{3}-\mathrm{PNC}$ & 12.6 & 25 \\
\hline PE-3wt. $\%-\mathrm{Al}_{2} \mathrm{O}_{3}$-PNC & 12.7 & 32 \\
\hline PE-5wt. $\%-\mathrm{Al}_{2} \mathrm{O}_{3}-\mathrm{PNC}$ & 12.3 & 26 \\
\hline PE-10wt. $\%-\mathrm{Al}_{2} \mathrm{O}_{3}-\mathrm{PNC}$ & 12.0 & 32 \\
\hline PE-1wt. $\%-\mathrm{C}_{8}-\mathrm{Al}_{2} \mathrm{O}_{3}-\mathrm{PNC}$ & 13.1 & 26 \\
\hline PE-3wt. $\%-\mathrm{C}_{8}-\mathrm{Al}_{2} \mathrm{O}_{3}-\mathrm{PNC}$ & 12.7 & 31 \\
\hline PE-5wt. $\%-\mathrm{C}_{8}-\mathrm{Al}_{2} \mathrm{O}_{3}-\mathrm{PNC}$ & 12.7 & 29 \\
\hline PE-10wt. $\%-\mathrm{C}_{8}-\mathrm{Al}_{2} \mathrm{O}_{3}-\mathrm{PNC}$ & 12.5 & 26 \\
\hline
\end{tabular}




\subsection{Diffusion}

During (polar) acetophenone sorption and desorption in extruded LDPE, only a minor (diffusion) concentration dependence was observed at 21 and $60^{\circ} \mathrm{C}$ (Figure 4). Therefore, the diffusion pre-exponent $D_{c 0}$ (Equation (5)), was just a little lower than the concentration independent diffusivity $D$ (Equation (3)) (Table 1). The presence of 1-12 wt.\% (0-4 vol.\%) spherical $\mathrm{Al}_{2} \mathrm{O}_{3}$ nanoparticles (with or without $\mathrm{C}_{8}$-coating) had a negligible impact on the acetophenone diffusion. At $21^{\circ} \mathrm{C}$, mass equilibrium was reached within $11 \mathrm{~h}$ (sorption) or $25 \mathrm{~h}$ (desorption), and the desorption diffusivity was $D$ (Equation (3) $=(5.1-6.3) \times 10^{-9} \mathrm{~cm}^{2} \mathrm{~s}^{-1}$. At $60^{\circ} \mathrm{C}$, the kinetic energy was higher and the free volume was larger than at $21^{\circ} \mathrm{C}$. Therefore, equilibrium was reached faster (1.4 for sorption and $2.7 \mathrm{~h}$ for desorption), and the diffusivity $D$ (Equation (3)) $=(95-100) \times 10^{-9} \mathrm{~cm}^{2} \mathrm{~s}^{-1}$ was 20 times higher than at $21^{\circ} \mathrm{C}$. Non-extruded LDPE (at 21 and $60^{\circ} \mathrm{C}$ ) had a diffusivity that was twice as large as extruded LDPE, due to its lower crystallinity (45.5 vs. $50 \%$ ) [47].
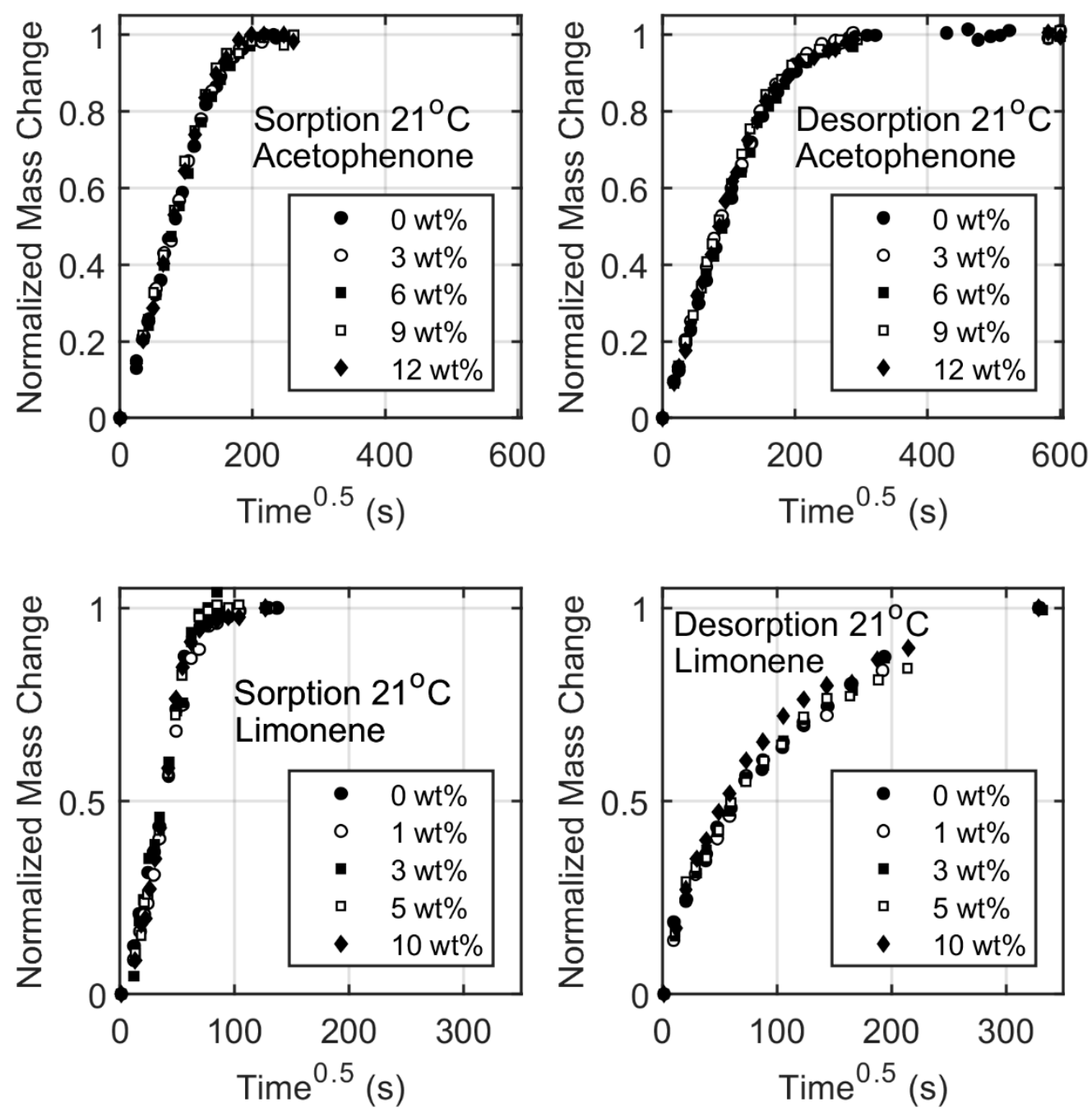

Figure 4. Sorption (left) and desorption (right) in $\mathrm{C}_{8}-\mathrm{Al}_{2} \mathrm{O}_{3}$ nanocomposites at $21^{\circ} \mathrm{C}$. Acetophenone (upper) and limonene (lower).

For (non-polar) limonene in extruded LDPE at $21^{\circ} \mathrm{C}$, slightly S-shaped sorption curves were observed (Figure 4). S-shaped curves are typically caused by the time-dependent and non-symmetric swelling of the polymer matrix $[40,45]$. The addition of nanoparticles $\left(\mathrm{Al}_{2} \mathrm{O}_{3}\right.$ or $\left.\mathrm{C}_{8}-\mathrm{Al}_{2} \mathrm{O}_{3}\right)$ did not change the limonene diffusivity $D$ (Equation (3)) $=(25-32) \times 10^{-9} \mathrm{~cm}^{2} \mathrm{~s}^{-1}$ (Table 2). Consequently, neither the equilibrium times for sorption $(\sim 1.5 \mathrm{~h})$ or desorption $(\sim 10.4 \mathrm{~h})$ were affected by the 
nanoparticles. The diffusivity for limonene was approximately 1 order of magnitude higher than for acetophenone, even although the limonene molecules were slightly larger. The higher limonene diffusivity was partly due to the non-polar nature of the limonene molecules, which reduces the adhesive interactions between the diffusing molecules and the polymer matrix, and partly due to the larger limonene solubility, which gives a more plasticized and swollen material with a larger free volume, thus facilitating penetrant diffusion.

It must be noted that the materials in this study were not crosslinked. Somewhat lower diffusivities are expected for the corresponding crosslinked LDPE nanocomposites, because crosslinking makes the polymer more rigid and decreases the accessible free volume and the mobility of the penetrant molecules.

\subsection{Influence of Particle Size on the Solubility}

Ceramics, such as $\mathrm{Al}_{2} \mathrm{O}_{3}$, are impermeable to many penetrant molecules. The solubility of acetophenone, limonene and water is, therefore, effectively zero in $\mathrm{Al}_{2} \mathrm{O}_{3}$. In contrast, the solubility $\left(S_{\mathrm{m}}\right)$ in the polymer matrix is larger than zero. Consequently, with sufficiently large $\mathrm{Al}_{2} \mathrm{O}_{3}$ particles, the composite solubility $S$ decreases proportionally with the particle volume fraction $\phi_{f}$, i.e., $S=$ $S_{m} \times\left(1-\phi_{f}\right)$. However, in several nanocomposite studies, the composite solubility increased with increasing nanoparticle content $[8,45]$. The reason for this discrepancy is that surface effects dominate at the nanoscale. All particle surfaces can attract (or repel) sorbent molecules, but nanoparticles have a much higher specific surface area than macroscopic particles. Therefore, the overall composite solubility depends on both the particle filler content and the specific particle surface area, $A_{0} / V_{0}$ $\left(\mathrm{m}^{2} / \mathrm{m}^{3}\right)$. For spherical particles with radius $r$, volume $V_{0}=4 \pi r^{3} / 3\left(\mathrm{~nm}^{3}\right)$ and surface area $A_{0}=4 \pi r^{2}$ $\left(\mathrm{nm}^{2}\right)$, it becomes $A_{0} / V_{0}=3 / r\left(\mathrm{~nm}^{-1}\right)$. The $\mathrm{Al}_{2} \mathrm{O}_{3}$ particles in this study had an average $r=25 \mathrm{~nm}$ [7]. At low-volume fractions of sufficiently small, well-dispersed polar nanoparticles, $S$ is expected to increase linearly with both $\phi_{f}$ and $A_{0} / V_{0}$. The solubility expressions for large and small particles can then be combined into one single predictive Equation (7):

$$
S\left(\phi_{f}\right)=\left(1-\phi_{f}\right) S_{m}+\phi_{f} k_{0} A_{0} / V_{0}=\left(1-\phi_{f}\right) S_{m}+\phi_{f} k_{0} 3 / r
$$

with matrix solubility $S_{m}(\mathrm{wt} . \%)$ and adsorption strength constant $k_{0}(\mathrm{wt} . \% \mathrm{~nm})$. With polar nanoparticles, $k_{0}$ is expected to be positive (=attractive) for polar molecules and zero or even negative (=repulsive) for non-polar molecules. For very large particles, $S$ will always decrease with $\phi_{f}$, but, for smaller particles, $S$ can either increase or decrease. The equation was in good agreement with the experimental solubility data of this study. For acetophenone, the constants were $S_{0}=2.07 \mathrm{wt} . \%$, $k_{0}=95 \mathrm{~nm}$ wt. $\%\left(\mathrm{C}_{8}-\mathrm{Al}_{2} \mathrm{O}_{3}\right)$ and $k_{0}=121\left(\mathrm{Al}_{2} \mathrm{O}_{3}\right)$. For limonene, they were $S_{0}=12.85 \mathrm{wt} . \%, k_{0}=0$ $\left(\mathrm{C}_{8}-\mathrm{Al}_{2} \mathrm{O}_{3}\right)$ and $k_{0}=150\left(\mathrm{Al}_{2} \mathrm{O}_{3}\right)$. In Figure 5 , the experimental acetophenone solubilities for $\mathrm{C}_{8}-\mathrm{Al}_{2} \mathrm{O}_{3}$ nanocomposites are plotted together with Equation (6), showing the predicted effect of the different particle sizes. A four-fold increase in particle radius from 25 to $100 \mathrm{~nm}$ changes the solubility slope from positive to negative, while a 16-fold increase (from 25 to $400 \mathrm{~nm}$ ) results in composites with negligible surface effects.

It should be noted that $k_{0}$ will only be constant at relatively low $\phi_{f}$ values. A maximum $\phi_{f}$ of $\sim 3$ vol.\% was used in this study. At higher filler fractions, when the particles start to influence each other, $k_{0}$ is expected to gradually decrease. 


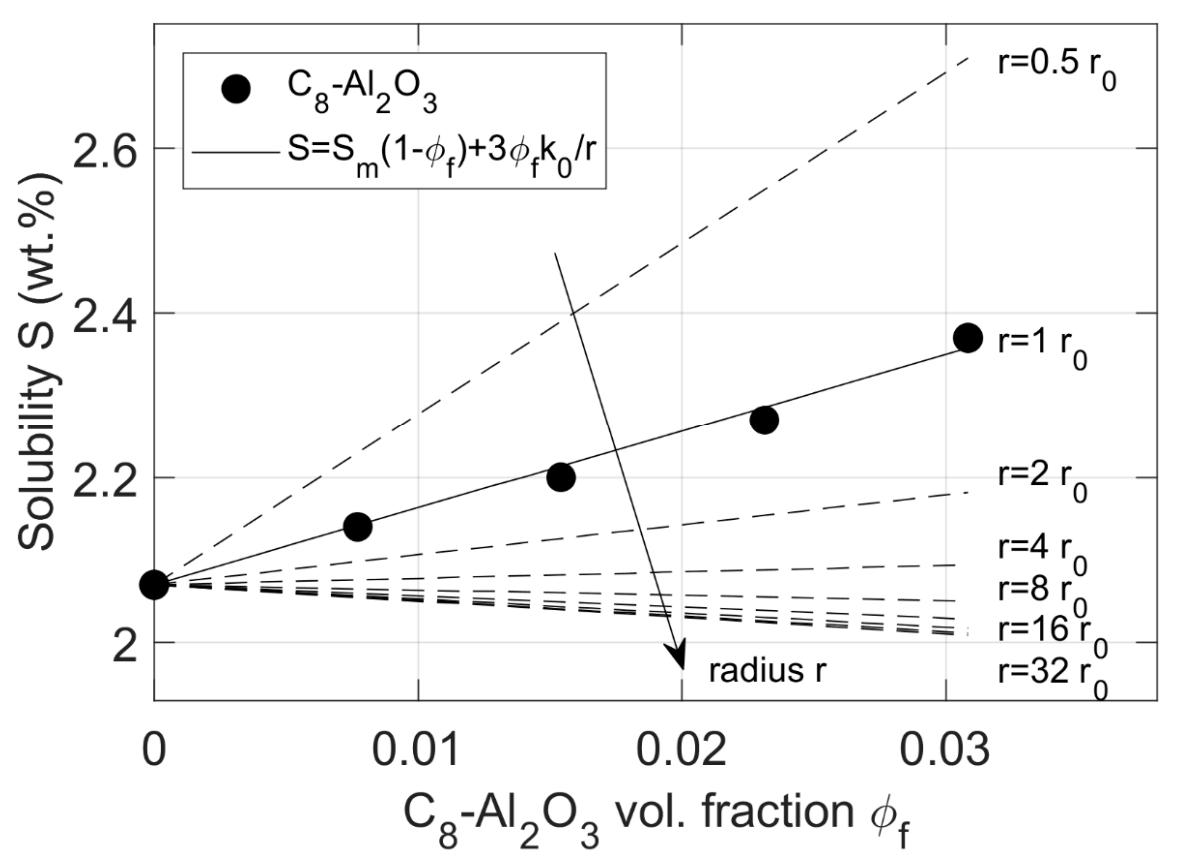

Figure 5. Acetophenone solubility $\left(21^{\circ} \mathrm{C}\right)$ as a function of $\mathrm{C}_{8}-\mathrm{Al}_{2} \mathrm{O}_{3}$ vol. fraction and nanoparticle radius $r$. The dots are the experimental data (radius $r_{0}=25 \mathrm{~nm}$ ), while the broken lines are predictions for other particle radii (Equation (6)).

A Monte Carlo model was used to assess the composite solubility at higher filler fractions of well-dispersed spherical particles. The composite was assumed to consist of three regions with distinctly different solubilities: the filler (with solubility $S_{f}=0$ ), the matrix (with solubility $S_{m}$ ) and the interphase between the filler and the matrix (with solubility $S_{I}$ ). Spherical particles with radius $r$, surrounded by an interphase with thickness $d$, were randomly placed in cubical simulation domains with size $(20 \mathrm{r})^{3}$. The average volume fractions of filler $\left(\phi_{f}\right)$, matrix $\left(\phi_{m}\right)$ and interphase $\left(\phi_{I}\right)$ were calculated for 100 simulation domains. The curves for $\phi_{I}$ versus $\phi_{f}$ were accurately fitted with third order polynomials (Figure 6a). In turn, the polynomial coefficients were fitted with two to four order polynomials as a function of $\delta=d / r$ (Figure 6b). The thin interlayer thicknesses $(d)$ resulted in nearly linear $\phi_{I}$ versus $\phi_{f}$ curves, whereas thicker interlayers resulted in curves with increasingly pronounced curvature. For systems with very thick interlayers, corresponding to very small particles, the interlayer volume fraction was no longer monotonically increasing in the range $0-25$ vol.\% particles. Generally, the scattering of the data was exceedingly small, because of the large size of the simulation domain and the large number of replicates, and the deviation between the simulation data points and the fitted curves was negligible. Using the data from Figure 6, the composite solubility $S$ becomes:

$$
\begin{aligned}
& S\left(\phi_{f}\right)=S_{f} \phi_{f}+S_{I} \phi_{I}+S_{m}\left(1-\phi_{f}-\phi_{I}\right) \\
& \phi_{I}=p_{1} \phi_{f}^{3}+p_{2} \phi_{f}^{2}+p_{3} \phi_{f} \\
& p_{1}=89.1 \delta^{4}-67.8 \delta^{3}-13.5 \delta^{2}+4.09 \delta \\
& p_{2}=-43.9 \delta^{3}+29.1 \delta^{2}-4.82 \delta \\
& p_{3}=4.7 \delta^{2}+2.36 \delta
\end{aligned}
$$

Equation (7) is valid in a larger filler fraction range than Equation (6), but has the drawback that two solubility measurements with different $r$ must be made in order to determine both the interphase solubility and the relative interphase thickness $\delta=d / r$. Equation (6) is only valid for small filler fractions (unless $r$ is large or the solute is nonpolar), but it is intuitive and easy to use, valid for non-spherical fillers, and the parameters can be determined using a single particle size. 


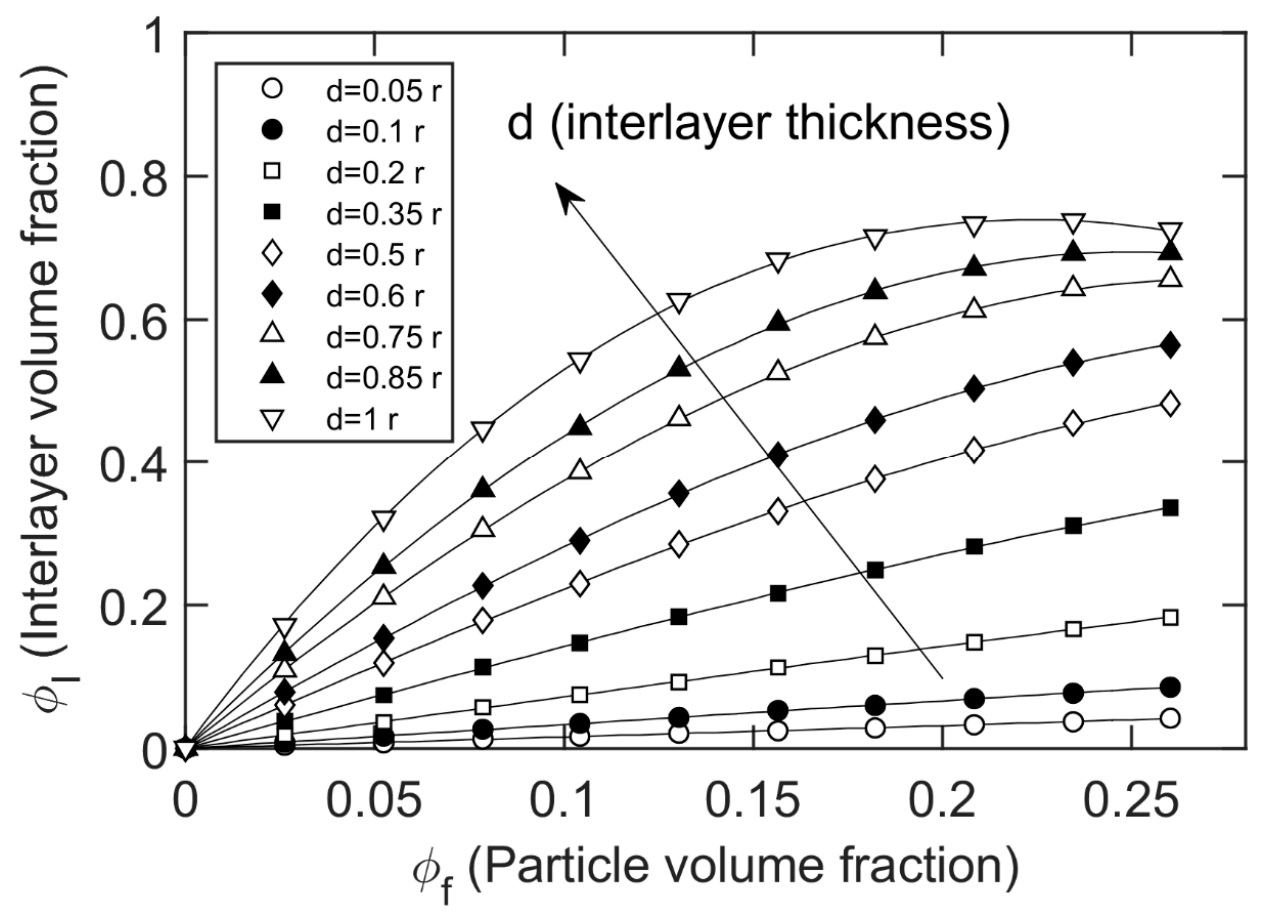

(a)

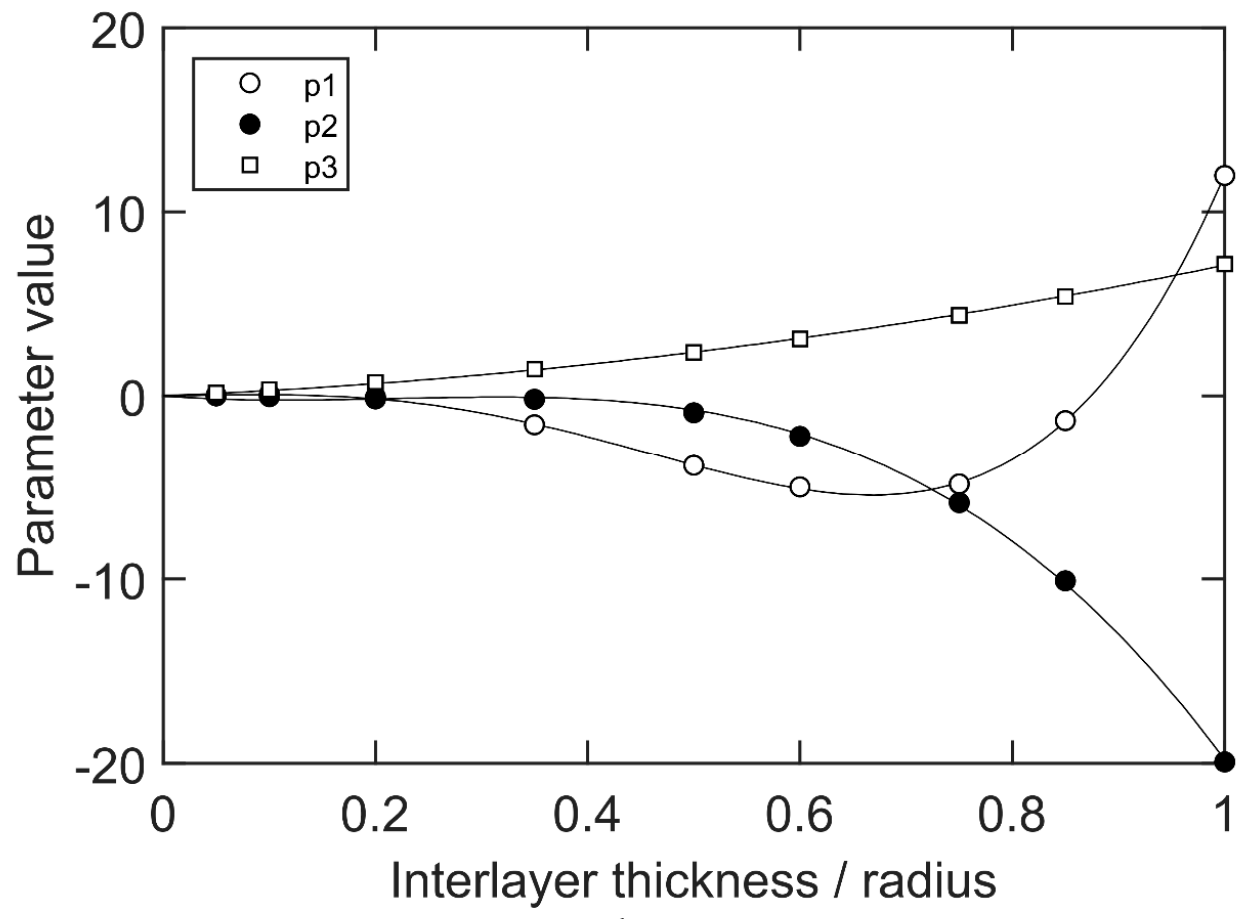

(b)

Figure 6. (a) interlayer fraction $\phi_{I}$ as a function of filler fraction $\phi_{f}$ and interlayer thickness $\mathrm{d}$. The solid lines are best fits with the polynomial $\phi_{I}=p_{1} \phi_{f}^{3}+p_{2} \phi_{f}^{2}+p_{3} \phi_{f}$. (b) fitting parameters p1-p3 (markers) and fourth order polynomial fits (lines).

\section{Conclusions}

The electrical conductivity of polyethylene (PE) is significantly reduced when small fractions of metal oxide nanoparticles are dispersed in it. A hypothesis is that (conductivity increasing) ions and polar molecules adsorb onto the nanoparticle surfaces, leading to the cleaning of the bulk of the polymer, and thereby decreasing the conductivity of the nanocomposite when compared to 
the pure PE. The solubility of (polar) acetophenone increased linearly with increasing nanoparticle content in $\mathrm{PE}-\mathrm{Al}_{2} \mathrm{O}_{3}$ and $\mathrm{PE}-\mathrm{C}_{8}-\mathrm{Al}_{2} \mathrm{O}_{3}$ nanocomposites, whereas the solubility of (non-polar) limonene showed a decrease with increasing nanoparticle content. The diffusivities of both acetophenone and limonene were essentially independent of the nanoparticle fraction in the composites. These findings strengthen the surface attraction hypothesis and provide fundamental information for the optimization of the electrical properties of insulation nanocomposites, especially for HVDC applications. Additionally, two novel equations for predicting composite solubility as a function of filler fraction, particle size and adsorption strength were derived. The first semi-empirical equation (Equation 6) can elegantly describe how particle size and particle filler fraction influence the composite solubility, only requiring the matrix solubility and the particle adsorption strength as input-i.e., only two solubility measurements at different filler fractions are required to determine the two constants. The second equation (Equation (7)), which is based on accurate data from the Monte Carlo simulations, describes the sorption in nano-composites with high particle filler fractions more correctly, but it has one additional unknown parameter that has to be determined with experimental measurements when compared to Equation (6).

Author Contributions: Conceptualization, S.L.H., M.E.K., M.S.H. and F.N.; Methodology, M.E.K., M.S.H. and F.N.; Software, F.N.; Validation, S.L.H., M.E.K., M.S.H. and F.N.; Formal Analysis, M.E.K., M.S.H. and F.N.; Investigation, M.E.K., S.L.H. and F.N.; Resources, M.S.H. and F.N.; Data Curation, S.L.H., M.E.K. and F.N.; Writing-Original Draft Preparation, S.L.H. and M.E.K.; Writing-Review \& Editing, F.N. and M.S.H.; Visualization, F.N. and R.T.O.; Supervision, F.N. and M.S.H.; Project Administration, F.N. and M.S.H.; Funding Acquisition, F.N. and M.S.H. All authors have read and agreed to the published version of the manuscript.

Funding: This research was funded by the Swedish research council grant number (VR 621-2014-5398) and through SweGRIDS, by the Swedish Energy Agency and ABB.

Conflicts of Interest: The authors declare no conflict of interest.

\section{References}

1. Montanari, G.C.; Laurent, C.; Teyssedre, G.; Campus, A.; Nilsson, U.H. From LDPE to XLPE: Investigating the change of electrical properties. Part I: Space charge, conduction and lifetime. IEEE Trans. Dielectr. Electr. Insul. 2005, 12, 438-446. [CrossRef]

2. Hanley, T.L.; Burford, R.P.; Fleming, R.J.; Barber, K.W. A general review of polymeric insulation for use in HVDC cables. IEEE Electr. Insul. Mag. 2003, 19, 13-24. [CrossRef]

3. Fothergill, J.C. The Coming of Age of HVDC Extruded Power Cables. Electr. Insul. Conf. (EIC) 2014, 124-137. [CrossRef]

4. Andersson, M.; Hynynen, J.; Andersson, M.; Englund, V.; Hagstrand, P.A.; Gkourmpis, T.; Müller, C. Highly insulating polyethylene blends for HVDC power cables. ACS Macro Lett. 2017, 6, 78. [CrossRef]

5. Pallon, L.; Hoang, A.; Pourrahimi, A.; Hedenqvist, M.; Nilsson, F.; Gubanski, S.; Gedde, U.W.; Olsson, R.T. The impact of $\mathrm{MgO}$ nanoparticle interface in ultra-insulating polyethylene nanocomposites for high voltage DC cables. J. Mater. Chem. 2016, 4, 8590-8601. [CrossRef]

6. Pourrahimi, A.M.; Hoang, T.A.; Liu, D.; Pallon, L.K.; Gubanski, S.; Olsson, R.T.; Gedde, U.W.; Hedenqvist, M.S. Highly Efficient Interfaces in Nanocomposites Based on Polyethylene and ZnO Nano/Hierarchical Particles: A Novel Approach toward Ultralow Electrical Conductivity Insulations. Adv. Mater. 2016, 28, 8651-8657. [CrossRef] [PubMed]

7. Liu, D.; Hoang, A.; Pourahimi, A.; Pallon, L.K.; Nilsson, F.; Gubanski, S.; Olsson, R.T.; Hedenqvist, M.S.; Gedde, U.W. Influence of nanoparticle surface coating on electrical conductivity of polyethylene/aluminium oxide nanocomposites for HVDC cable insulations. IEEE Trans. Dielectr. Electr. Insul. 2017, 24. [CrossRef]

8. Nilsson, F.; Karlsson, M.; Pallon, L.; Giacinti, M.; Olsson, R.T.; Venturi, D.; Gedde, U.W.; Hedeqvist, M.S. Influence of water update on the electrical DC-conductivity of insulating LDPE/MgO nanocomposites. Compos. Sci. Technol. 2017, 152, 11-19. [CrossRef]

9. Pourrahimi, A.M.; Olsson, R.T.; Hedenqvist, M.S. The Role of Interfaces in Polyethylene/Metal-Oxide Nanocomposites for Ultrahigh-Voltage Insulating Materials. Adv. Mater. 2017, 30. [CrossRef] 
10. Lewis, T. Charge Transport in Polyethylene Nano Dielectrics. IEEE Trans. Dielectr. Electr. Insul. 2014, 21, 497-502. [CrossRef]

11. Nelson, J. Dielectric Polymer Nanocomposites; Springer: New York, NY, USA, 2014.

12. Gao, Y.; Xu, B.; Wang, X.; Jia, T. Charge transport in low density polyethylene based micro/nano-composite with improved thermal conductivity. J. Phys. D Appl. Phys. 2019, 52, 285-302. [CrossRef]

13. Tian, F.; Lei, Q.; Wang, X.; Wang, Y. Effect of deep trapping states on space charge suppression in polyethylene/ZnO nanocomposite. Appl. Phys. Lett. 2011, 99, 142903. [CrossRef]

14. Liu, D.; Pourrahimi, A.; Pallon, L.; Sánchez, C.C.; Olsson, R.T.; Hedenqvist, M.S.; Fogelström, L.; Malmström, E.; Gedde, U.W. Interactions between a phenolic antioxidant, moisture, peroxide and crosslinking by-products with metal oxide nanoparticles in branched polyethylene. Polym. Degrad. Stab. 2016, 125, 21-32. [CrossRef]

15. Wang, S.J.; Zha, J.W.; Li, W.K.; Dang, Z.M. Distinctive electrical properties in sandwich structured Al2O3/LDPE nanocomposites. Appl. Phys. Lett. 2016, 108, 092902. [CrossRef]

16. Wang, S.J.; Zha, J.W.; Wu, Y.H.; Ren, L.; Dang, Z.M.; Wu, J.I. Preparation, microstructure and properties of polyethylene/aluminium nanocomposites for HVDC insulation. IEEE Trans. Dielectr. Electr. Insul. 2015, 22, 3350-3356. [CrossRef]

17. Zha, J.W.; Yan, H.D.; Li, W.K.; Zhang, D.L.; Dang, Z.M. Sandwiched structure effect on space charge chargecteristics of aluminium/polyethylene nanocompomposites. IEEE Trans. Dielectr. Electr. Insul. 2017, 24, 1365-1371.

18. Zhou, Y.; Hu, J.; Dang, B.; He, J. Effect of different nanoparticles on tuning electrical properties of polypropylene nanocomposites. IEEE Trans. Dielectr. Electr. Insul. 2017, 24, 1380-1389. [CrossRef]

19. Ciuprina, F.; Zaharescu, T.; Plesa, I. Effects of y-radiation on dielectric properties of $\mathrm{LDPE}_{-} \mathrm{Al}_{2} \mathrm{O}_{3}$ nanocomposites. Radiat. Phys. Chem. 2013, 84, 145-150. [CrossRef]

20. Elimat, Z.M.; Zihlif, A.M.; Schulte, K.I.; de la Vega, A.; Gagosta, G. Electrical Characterization of polyethylene oxide alumina composite. J. Thermoplast. Compos. Mater. 2011, 26, 176-192. [CrossRef]

21. Panaitescu, D.; Ciuprina, F.; Iorga, M.; Frone, A.; Radovici, C.; Ghiurea, M.; Sever, S.; Plesa, I. Effects of $\mathrm{SiO}_{2}$ and $\mathrm{Al}_{2} \mathrm{O}_{3}$ nanofillers on polyethylene properties. J. Appl. Polym. Sci. 2011, 122, 1921-1935. [CrossRef]

22. Jose, J.P.; Thomas, S. Aluminia-clay nanoscale hybrid filler assembling in cross-linked polyethylene based nanocomposites: Mechanics and thermal properties. Phys. Chem. Chemphys. 2014, 16, 14730. [CrossRef] [PubMed]

23. Zhang, S.; Cao, X.Y.; Ma, Y.M.; Ke, Y.C.; Zhang, J.K.; Wang, F.S. The effects of particle size and content on the thermal conductivity and mechanical properties of $\mathrm{Al}_{2} \mathrm{O}_{3}$ /high density polyethylene (HDPE) composites. Polym. Lett. 2011, 5, 581-590. [CrossRef]

24. Park, Y.J.; Kwon, J.H.; Sin, J.Y.; Hwang, J.N.; Seo, C.W.; Kim, J.H.; Lim, K.J. DC conductivity and breakdown characteristics of $\mathrm{Al}_{2} \mathrm{O}_{3}$ /crosslinked polyethylene nanocomposites for high voltage direct current transmission cable insulation. Jpn. J. Appl. Phys. 2014, 53, 08NL05. [CrossRef]

25. Tanaka, T.; Imai, T. Advances in nanodielectric materials over the past 50 years. IEEE Electr. Insul. Mag. 2013, 12, 10-23. [CrossRef]

26. Reed, C. Advances in polymer dielectrics over the past 50 years. IEEE Electr. Insul. Mag. 2013, 12, 58-62. [CrossRef]

27. Teyssedre, G.; Laurent, C. Advances in high-field insulating polymeric materials over the past 50 years. IEEE Electr. Insul. Mag. 2013, 12, 26-36. [CrossRef]

28. Zhou, Y.; Peng, S.; Hu, J.; He, J. Polymeric insulation materials for HVDC cables: Development, challenges and future prespective. IEEE Trans. Dielectr. Electr. Insul. 2017, 24, 1308-1381. [CrossRef]

29. Plesa, I.; Nothingher, P.V.; Schlögl, S.; Sumereder, C.; Muhr, M. Review: Properties of polymer composites used in high voltage applications. Polymers 2016, 8, 173. [CrossRef]

30. Plesa, I.; Nothingher, P.V.; Stancu, C.; Wiesbrock, F.; Schlögl, S. Review: Polyethylene nanocomposites for power cable insulations. Polymers 2019, 11, 24. [CrossRef]

31. Chen, L.; Huan, T.D.; Ramprasad, R. Electronic structure of polyethylene: Role of chemical, morphological and interfacial complexity. Sci. Rep. 2017, 7, 6128. [CrossRef]

32. National Library of Medicine-National Institutes of Health, NIH U.S. National Library of Medicine. Limonene. Available online: https:/pubchem.ncbi.nlm.nih.gov/compound/Limonene (accessed on 29 August 2019). 
33. National Library of Medicine-National Institutes of Health, NIH U.S. National Library of Medicine. Acetophenone. Available online: https://pubchem.ncbi.nlm.nih.gov/compound/Acetophenone (accessed on 29 August 2019).

34. Karlsson, M.; Xu, X.; Gaska, K.; Hillborg, H.; Gubanski, S.; Gedde, U.W. DC Conductivity Measurements of LDPE: Influence of Specimen Preparation Method and Polymer Morphology. Proc. Nord. Insul. Symp. 2017, 25. [CrossRef]

35. Liu, D.; Pourrahimi, A.M.; Olsson, R.T.; Hedenqvist, M.S.; Gedde, U.W. Influence of nanoparticle surface treatment on particle dispersion and interfacial adhesion in low-density polyethylene/aluminium oxide nanocomposites. Eur. Polym. J. 2015, 66, 67-77. [CrossRef]

36. Liu, D.; Pourrahimi, A.M.; Pallon, L.K.H.; Andersson, R.L.; Hedenqvist, M.S.; Gedde, U.W.; Olsson, R.T. Morphology and properties of silica-based coatings with different functionalities for $\mathrm{Fe}_{3}, \mathrm{ZnO}$ and $\mathrm{Al}_{2} \mathrm{O}_{3}$ nanoparticles. RSC Adv. 2015, 5, 48094. [CrossRef]

37. Gedde, U.W. Polymer Physics; Springer: Stockholm, Sweden, 1999.

38. Wunderlich, B.; Bauer, H. Heat Capacities of Linear High Polymers. Adv. Polym. Sci. 1970, 7, 151. [CrossRef]

39. Wunderlich, B. Heat of Fusion of Polyethylene. J Polym. Sci. Part A 1967, 2, 5. [CrossRef]

40. Panayiotis, J.K.; Baptiste, M.J. Thermal and Structural Properties of Fusion Related Materials. Available online: http://www-ferp.ucsd.edu/LIB/PROPS/PANOS/al2o3.html (accessed on 29 August 2019).

41. Crank, J. The Mathematics of Diffusion, 2nd ed.; Clarendon Press: Oxford, UK, 1986.

42. Hedenqvist, M.S.; Ohrlander, M.; Palmgren, R.; Albertsson, A. Multi-layer modelling of diffusion of water in acrylamide-grafted aliphatic polyesters. Polym. Eng. Sci. 1998, 38, 1313-1323. [CrossRef]

43. Hedenqvist, M.S.; Gedde, U.W. Parameters affecting the determination of transport kinetics data in highly swelling polymers above $\mathrm{T}_{\mathrm{g}}$. Polymer 1999, 40, 2381-2393. [CrossRef]

44. Bakhouya, A.; Brouzi, A.E.; Bouzon, J.; Vergnaud, J.M. Modelling the Process of Desorption of a Liquid from a Sheet of Polymer by Considering the Diffusion and Evaporation and the Change in Dimension. Plast. Rubber Comp. Proc. Appl. 1993, 19, 77.

45. Nordell, P.; Nilsson, F.; Hedenqvist, M.S.; Hillborg, H.; Gedde, U.W. Water transport in aluminium oxide-poly (ethylene-co-butyl acrylate) nanocomposites. Eur. Polym. J. 2011, 47, 2208-2215. [CrossRef]

46. Nilsson, F.; Hallstensson, K.; Johansson, K.; Umar, Z.; Hedenqvist, M.S. Predicting Solubility and Diffusivity of Gases in Polymers under High Pressure: N2 in Polycarbonate and Poly(ether-ether-ketone). Ind. Eng. Chem. Res. 2013, 52, 8655-8663. [CrossRef]

47. Nilsson, F.; Gedde, U.W.; Hedenqvist, M.S. Penetrant diffusion in polyethylene spherulites assessed by a novel off-lattice Monte Carlo technique. Eur. Polym. J. 2009, 45, 3409-3417. [CrossRef] 